\title{
Effect of Methoxy Substituents on Wet Peroxide Oxidation of Lignin and Lignin Model Compounds: Understanding the Pathway to $\mathrm{C}_{4}$ Dicarboxylic Acids
}

\author{
Carlos A. Vega-Aguilar, M. Filomena Barreiro, and Alírio E. Rodrigues*
}

Cite This: Ind. Eng. Chem. Res. 2021, 60, 3543-3553

Read Online

ACCESS | Lلll Metrics \& More | 国 Article Recommendations ｜ sl Supporting Information

ABSTRACT: Lignin depolymerization through peroxide oxidation produces dicarboxylic acids (DCA), especially $\mathrm{C}_{4}$-DCA, like succinic acid. In this work, the effect of methoxy substituents on $\mathrm{C}_{4}$-DCA production using peroxide oxidation of lignin model compounds ( $p$-hydroxybenzoic acid, vanillic acid, and syringic acid) and hardwood and softwood lignin samples was studied. It was concluded that methoxy substituents increased the reactivity toward peroxide oxidation. The succinic acid yield was higher for the model compounds with fewer methoxy groups, achieving 5.8 wt $\%$ of succinic acid for $p$-hydroxybenzoic acid. For Eucalyptus globulus kraft lignin (hardwood lignin with guaiacyl and syringyl units), an increased reactivity was

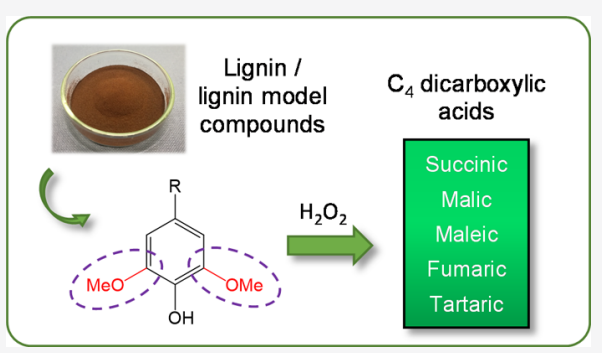
verified, and more succinic acid (3.5 wt \%) was produced in a shorter time, comparatively with Indulin AT lignin (softwood lignin, with only guaiacyl units), which produced 2.7 wt $\%$. This evidence suggests that E. globulus kraft lignin might be a better raw material than Indulin AT for succinic acid production by peroxide oxidation.

\section{INTRODUCTION}

A lignocellulosic biomass biorefinery has proven to be a favorable alternative to reduce the fossil fuel dependence of the chemical industry. ${ }^{1}$ Lignin is present in all lignocellulosic biomass, at contents that vary depending on their source. Structurally, it is composed of three phenylpropane units, known as $p$-hydroxyphenyl $(\mathrm{H})$, guaiacyl $(\mathrm{G})$, and syringyl (S) units. ${ }^{2}$ These units can be identified in the lignin structure, respectively, as derivatives of p-coumaryl alcohol, coniferyl alcohol, and sinapyl alcohol moieties. The main difference between these structures relies on the methoxy substituents located in the ortho position relative to the hydroxyl group in the phenolic ring, as shown in Figure la. The abundance of each monomer in the lignin is related to plant taxonomy, as shown in Table 1 . The ratio between monomers is a relevant parameter because each monomer has a different chemical behavior and distinct possibilities of interlinking. ${ }^{3}$ Most of the links between monomers are alkyl- and aryl-ether linkages (60-70\%), C-C linkages ( $25-35 \%)$, and some ester bonds $(<5 \%)$, being the most common ones the $\beta$-O- $4, \alpha-\mathrm{O}-4, \beta-\beta, \beta$ $5,5-5, \beta-1$, and the $4-\mathrm{O}-5$, which lead to a complex heterogeneous structure that is difficult to isolate and depolymerize. ${ }^{4,5}$ Kraft lignin is obtained from kraft pulping processes, which not only modify the structure of native lignin through cleavage of $\alpha$ - and $\beta$-ether bonds, but also causes condensation as carbon-carbon bonds. In these processes, lignin is burnt to produce energy and recover chemicals. However, kraft lignin can also be valorized into value-added products. ${ }^{4,6}$
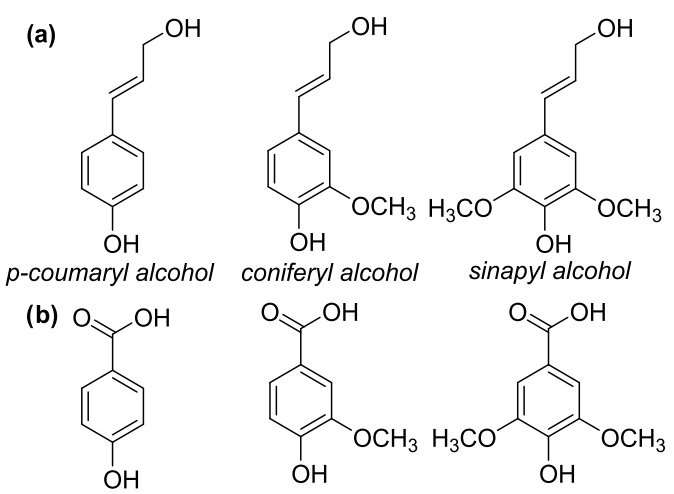

p-hydroxybenzoic acid Vanillic acid

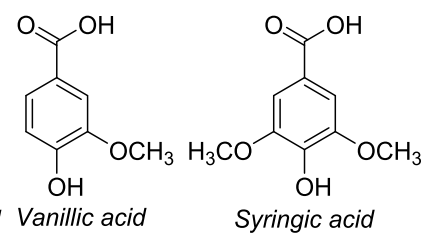

Figure 1. Structures of (a) monolignol monomers and (b) model compounds used for this work.

Lignin has been proposed as a feedstock for several products after depolymerization, which can be achieved by oxidation, reduction, pyrolysis, hydrotreatment, enzymatic hydrolysis, and many other chemical and biological treatments. ${ }^{7-10}$ Phenolic products, such as phenol, vanillin, syringaldehyde, and catechol, among others, have been the main focus in lignin

Received: October 17, 2020

Revised: January 1, 2021

Accepted: January 5, 2021

Published: January 18, 2021

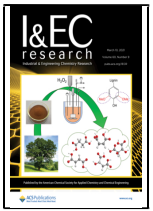


Table 1. Approximate Composition (\%) of Some Lignin Classes, Depending on Plant Taxonomy

phenylpropane units
softwood lignin
hardwood lignin
grass lignin

guaiacylpropane (\%)
95
50
70

syringylpropane (\%)
1
50
25

p-hydroxyphenylpropane (\%)

4

2

5

${ }^{a}$ Reprinted with permission from Brunow, G. ${ }^{3}$ Copyright 2008. John Wiley and Sons.

depolymerization. ${ }^{11,12}$ However, due to higher availability and low commercial use of lignin, the study of this renewable raw material as a feedstock for the production of a diversity of aliphatic compounds (e.g., adipic acid, succinic acid, cyclohexane), which are nowadays produced by petrochemical routes or biochemical pathways using fermentable sugars, has become of high interest. ${ }^{2}$ Strong oxidative depolymerization can cause a ring-opening reaction, producing several $\mathrm{C}_{1}$ to $\mathrm{C}_{6}$ acids, especially dicarboxylic acids (DCA), like adipic, muconic, succinic, maleic, and oxalic acids. ${ }^{13-16}$ Peroxide oxidation has been considered more efficient for aromatic ring cleavage than $\mathrm{O}_{2}$ oxidation because it avoids mass-transfer limitations. Moreover, $\mathrm{H}_{2} \mathrm{O}_{2}$ releases free radicals, which enhance lignin degradation in a shorter time under less severe conditions. ${ }^{17,18}$ Several of these dicarboxylic acids have shown relevance as feedstocks for polymers, cosmetics, and the food industry. They are currently under study aiming to enhance their production through chemical and biological lignin depolymerization. ${ }^{18} \mathrm{C}_{4}$-DCA (succinic, maleic, malic, fumaric, and tartaric acids) (Figure 2), the main diacids obtained in the

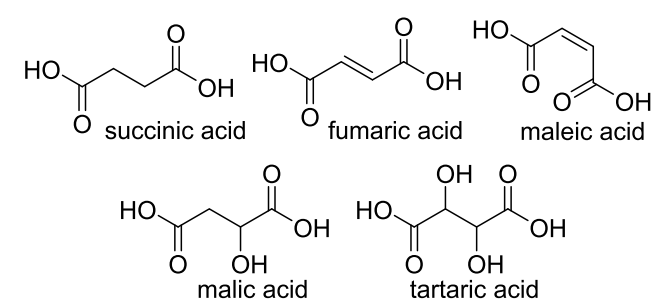

Figure 2. Structures of $\mathrm{C}_{4}$ dicarboxylic acids (DCA).

oxidation, and oxalic acid, have great importance as renewable building blocks for the future high-value bio-based chemicals and materials. ${ }^{19}$ In particular, succinic acid has attracted special interest due to its application in the chemical industry (as a surfactant, ion chelator, etc.), food industry (acidulant, flavoring additive, and antimicrobial agent), and as an intermediate for chemical and materials production. ${ }^{20}$

Initial studies on oxidation of lignin model compounds and lignin revealed the formation of $\mathrm{C}_{4}$-DCA after the ring-opening reaction in the alkaline pulping and peroxide bleaching processes. $^{21}$ Those studies were used to explain lignin degradation through the pulping process but were not focused on DCA production. Therefore, the quantities reported in those studies were negligible or not specified at all. More recently, different studies presented the noncatalyzed production of dicarboxylic acids from oxidation of lignin and lignin model compounds using $\mathrm{H}_{2} \mathrm{O}_{2}$. However, none of these studies focused on analyzing the impact of the model compounds' structural features on the DCA yields. ${ }^{14,22-24}$ A higher DCA (oxalic, malonic, and succinic acids) yield has been related to a lower ratio of aromatic to aliphatic functional groups when bagasse lignin was catalytically oxidized with $\mathrm{H}_{2} \mathrm{O}_{2}$ and sodium percarbonate or chalcopyrite. ${ }^{25} \mathrm{Ma}$ et al. (2018) reported the oxidative conversion of several biorefinery lignins to mono- meric phenols and dicarboxylic acids (described as a mixture of $\mathrm{C}_{2}-\mathrm{C}_{6}$ acids) using chalcopyrite-catalyzed peroxide oxidation, showing that the DCA yield increased as the methoxy group content and aromatic hydroxyl groups increased. ${ }^{26}$ However, this model did not discriminate $\mathrm{C}_{4}$-DCA from other acids, especially from $\mathrm{C}_{2}-\mathrm{C}_{3}$ acids, which are degradation products of $\mathrm{C}_{4}$-DCA formation. In fact, until now, there is no clear evidence showing the best lignin structural unit to obtain a specific dicarboxylic acid by peroxide oxidation. This can point out the most appropriate lignin for depolymerization toward a lignin-based chemical platform.

In the present work, the effect of the methoxy substituents in the aromatic ring was studied, with the aim of obtaining dicarboxylic acids, focused on $\mathrm{C}_{4}$-DCA (mainly succinic, malic, fumaric, maleic, and tartaric acids), and specifically succinic acid. This effect was analyzed on p-hydroxybenzoic, vanillic, and syringic acids, which are lignin model compounds resembling the lignin structural monomeric units, namely, by presenting a different number of methoxy substituents in the ortho position to the phenolic $\mathrm{OH}$ group, as shown in Figure 1b. Moreover, this study was extended to two kraft lignins with different $\mathrm{G} / \mathrm{S} / \mathrm{H}$ ratios (a hardwood and a softwood sample).

\section{METHODOLOGY}

Materials. All chemical reagents were purchased from commercial sources and used without further purification. The following reagents were purchased from Sigma-Aldrich Co. LLC.: $p$-hydroxybenzoic acid ( $p$ HBA) (>99\%), vanillic acid (VA) (97\%), syringic acid (SA) (>95\%), DL-malic acid $(\geq 99.0 \%)$, fumaric acid $(\geq 99.0 \%)$, maleic acid $(>99 \%)$, malonic acid $(>99 \%)$, oxalic acid dihydrate $(\geq 99.0 \%)$, succinic acid $(\geq 99.0 \%)$, acetic acid glacial $(>99 \%)$, N,O-bis(trimethylsilyl)trifluoroacetamide $(\geq 99.0 \%)$, trimethylchlorosilane (>98\%), and pyridine (>99.0\%). Other reagents were purchased from different suppliers: formic acid (Chem-labs, $>99 \%$ ), acetonitrile (VWR, high-performance liquid chromatography (HPLC) grade), sulfuric acid (Chem-labs, 95-97\% p.a.), sodium hydroxide (Merck, p.a.), and hydrogen peroxide solution (Fluka, >30\% p.a.). Gases helium (ALPHAGAZ 1 $\mathrm{He}$ ) and argon (ALPHAGAZ Ar 1) were supplied by Air Liquide.

Two lignins were used: Indulin AT, a softwood lignin, commercialized by MeadWestvaco Corporation, with a $S / G / H$ ratio of $0: 97: 3 .^{27}$ The hardwood lignin was isolated from the black liquor obtained from a Eucalyptus globulus kraft pulping mill (The Navigator Company, Portugal). This lignin has a S/ $\mathrm{G} / \mathrm{H}$ ratio of $65: 29: 6 .^{28}$ Table 2 shows some properties of these two studied lignins.

Experimental Methods. Oxidation Procedure. Oxidation reactions were conducted in a glass-jacketed $1 \mathrm{dm}^{3}$ Büchi autoclave (Figure 3). A Lauda E300 thermostatic bath was used to control heating, keeping the reactor at 393-413 K. All model compounds (vanillic acid [VA], syringic acid [SA], and $p$-hydroxybenzoic acid $[p \mathrm{HBA}])$ were used at a concentration of $10 \mathrm{~g} / \mathrm{L}$ and an initial $\mathrm{pH}$ of 7.0, adjusted with $\mathrm{NaOH}$ or 
Table 2. Properties of the Studied Lignins

\begin{tabular}{lcc}
\multicolumn{1}{c}{ lignin } & $\begin{array}{c}\text { lignin isolated from kraft } \\
\text { black liquor (hardwood) }\end{array}$ & $\begin{array}{c}\text { Indulin AT } \\
\text { (softwood) }^{27,29}\end{array}$ \\
S/G/H ratio & $65: 29: 6$ & $0: 97: 3$ \\
total lignin (wt \%) & 66 & 92.2 \\
$\begin{array}{c}\text { weight-average molecular } \\
\text { weight }\left(M_{\mathrm{w}}\right)(\mathrm{g} / \mathrm{mol})\end{array}$ & 10323 & 4290 \\
$\begin{array}{c}\text { number-average molecular } \\
\text { weight }\left(M_{\mathrm{n}}\right)(\mathrm{g} / \mathrm{mol})\end{array}$ & 8768 & 530 \\
\hline
\end{tabular}

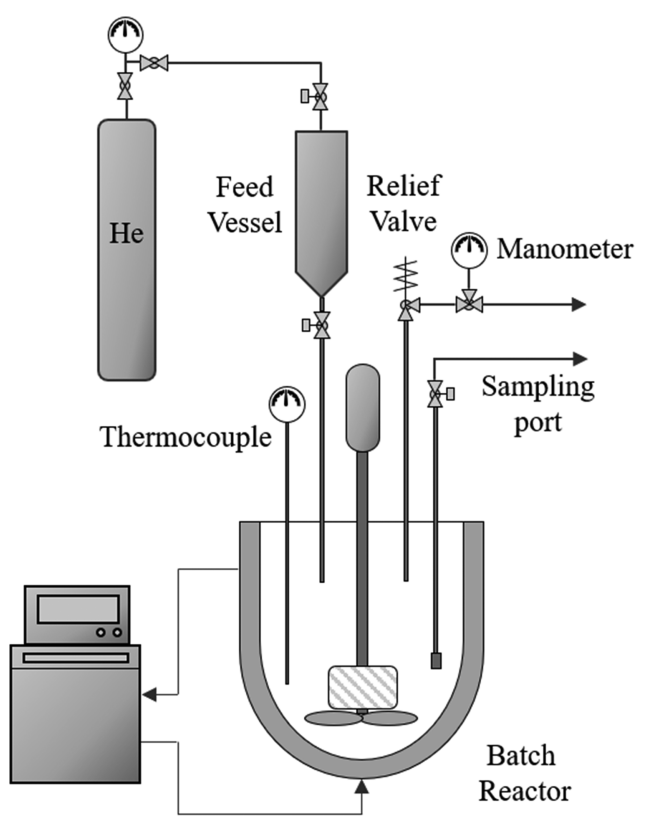

Figure 3. Scheme of the setup used for the oxidation reactions.

$\mathrm{H}_{2} \mathrm{SO}_{4}(1.0 \mathrm{~mol} / \mathrm{L})$, as needed. Lignin samples $(10 \mathrm{~g} / \mathrm{L})$ were solubilized in a $0.1 \mathrm{~mol} / \mathrm{L}$ phosphate buffer to ensure complete solubilization throughout the reaction. The solution $(400 \mathrm{~mL})$ was placed in a batch reactor, then closed, and pressurized with helium. Heat was applied to reach the desired temperature. A $40 \mathrm{~mL}$ aliquot of $30 \mathrm{vol} \% \mathrm{H}_{2} \mathrm{O}_{2}$ was loaded into the feed vessel, which was closed and pressurized with $\mathrm{He}$. When the temperature was steady, $\mathrm{H}_{2} \mathrm{O}_{2}$ was introduced into the reactor, and the reaction started. Samples were taken manually for $4 \mathrm{~h}$ at intervals of $10-30 \mathrm{~min}$. The stirring speed was fixed at 800 $\mathrm{rpm}$, and a maximum pressure of 9.0 bar was used. Signals of the thermocouple and pressure inside the reactor were registered using an acquisition board and LabVIEW software. All experiments were done in duplicate.

All of the reactions were performed using $40 \mathrm{~mL}$ of $30 \mathrm{vol} \%$ $\mathrm{H}_{2} \mathrm{O}_{2}(0.39 \mathrm{~mol})$, which provided the molar quantities needed to achieve complete mineralization of the three used model compounds, according to eq 1 (VA, $0.023 \mathrm{~mol}$, which needed $0.38 \mathrm{~mol} \mathrm{H}_{2} \mathrm{O}_{2}$ ), eq 2 ( $p \mathrm{HBA}, 0.028 \mathrm{~mol}$, which needed 0.39 mol $\mathrm{H}_{2} \mathrm{O}_{2}$ ) and eq 3 ( $\mathrm{SA}, 0.019 \mathrm{~mol}$, which needed $0.34 \mathrm{~mol}$ $\mathrm{H}_{2} \mathrm{O}_{2}$ ). Even so, $\mathrm{H}_{2} \mathrm{O}_{2}$ cannot be considered as the limiting reagent because not all of the model compound molecules were mineralized but converted to low-molecular-weight compounds. The same amount of oxidant was used for lignin since preliminary tests showed that a higher amount of the oxidant caused $\mathrm{C}_{4}$-DCA degradation. The oxidant was added precisely when the solution was at the setpoint temperature and the system pressurized to avoid $\mathrm{H}_{2} \mathrm{O}_{2}$ degradation while heating.

$$
\begin{aligned}
& \mathrm{C}_{8} \mathrm{H}_{8} \mathrm{O}_{4}+16 \mathrm{H}_{2} \mathrm{O}_{2} \rightarrow 8 \mathrm{CO}_{2}+20 \mathrm{H}_{2} \mathrm{O} \\
& \mathrm{C}_{7} \mathrm{H}_{6} \mathrm{O}_{3}+14 \mathrm{H}_{2} \mathrm{O}_{2} \rightarrow 7 \mathrm{CO}_{2}+17 \mathrm{H}_{2} \mathrm{O} \\
& \mathrm{C}_{9} \mathrm{H}_{10} \mathrm{O}_{5}+18 \mathrm{H}_{2} \mathrm{O}_{2} \rightarrow 9 \mathrm{CO}_{2}+23 \mathrm{H}_{2} \mathrm{O}
\end{aligned}
$$

Analytical Methods. Sample Preparation for Chromatographic Analysis and Lignin Quantification. Model compound oxidation samples in aqueous solution were acidified with $2 \mathrm{~mol} / \mathrm{L} \mathrm{H}_{2} \mathrm{SO}_{4}$ to $\mathrm{pH} \sim 2$, diluted as needed, and filtered through a $0.22 \mu \mathrm{m}$ pore-size filter. Lignin samples were acidified to $\mathrm{pH} \sim 2$, then heated at $40{ }^{\circ} \mathrm{C}$ to coagulate the acidinsoluble lignin, followed by centrifugation at $5000 \mathrm{rpm}$ for 15 min. The insoluble lignin was dried at $100{ }^{\circ} \mathrm{C}$ overnight to quantify the acid-insoluble lignin. The acidic supernatant was used for carboxylic acid and acid-soluble lignin quantification. Acid-soluble lignin was measured by UV spectrophotometry at $240 \mathrm{~nm}$, based on a calibration curve done with the acidsoluble lignin from the original lignin. Lignin conversion was measured as the sum of the acid-insoluble and acid-soluble lignins. The $\mathrm{pH}$ was measured for all samples before acidification using a calibrated VWR pH110 equipment. The gaseous compounds were not quantified in this study.

Quantification by High-Performance Liquid Chromatography (HPLC). Carboxylic acids were quantified by highperformance liquid chromatography (HPLC) using a Shimadzu UFLC, equipped with a diode array detector (210 and 260 $\mathrm{nm})$, refraction index detector (RI), and a Phenomenex Rezex $\mathrm{ROA} \mathrm{H}^{+}$column $(300 \mathrm{~mm} \times 7.8 \mathrm{~mm})$ and precolumn $(50 \mathrm{~mm}$ $\times 7.8 \mathrm{~mm})$. The column was operated at $50{ }^{\circ} \mathrm{C}$ using a gradient flow of $4 \mathrm{mmol} / \mathrm{L} \mathrm{H}_{2} \mathrm{SO}_{4}$ and a solution of $15 \%$ acetonitrile in $4 \mathrm{mmol} / \mathrm{L} \mathrm{H}_{2} \mathrm{SO}_{4}$, at a flow rate of $0.5 \mathrm{~mL} / \mathrm{min}$, and an injection volume of $20 \mu \mathrm{L}$. Carboxylic acids were identified and quantified using calibration curves prepared with standards of each acid.

Quantified acids are expressed as $\mathrm{C}_{4}$-DCA (succinic, malic, maleic, fumaric, and tartaric acids), other DCA (malonic and oxalic acids), total DCA ( $\mathrm{C}_{4}$-DCA + other DCA), and MCA (monocarboxylic acids: acetic and formic acid). Aromatic carboxylic acid (CA) is the sum of $p \mathrm{HBA}, \mathrm{VA}$, and SA.

Gas Chromatography-Mass Spectroscopy (GC-MS) Analysis. Qualitative analysis of the compounds produced at low concentrations was done with GC-MS to understand the degradation pathway of lignin and model compounds to $\mathrm{C}_{4^{-}}$ DCA. For that, a $1.0 \mathrm{~mL}$ of the sample (prefiltered through a $0.22 \mu \mathrm{m}$ filter) was lyophilized in a glass tube. The solids were dissolved in $150 \mu \mathrm{L}$ of pyridine. Then, $150 \mu \mathrm{L}$ of BSTFA and $50 \mu \mathrm{L}$ of TMCS were added. The mixture was mixed and placed in an oil bath at $80{ }^{\circ} \mathrm{C}$ for $30 \mathrm{~min}$ to allow complete silylation. The samples were immediately cooled in an ice bath and diluted to $1.0 \mathrm{~mL}$ with anhydrous acetonitrile. Derivatized samples were analyzed in a Shimadzu GC-MS-TQ8040, fitted with a Restek Rxi-5Sil MS column $(30 \mathrm{~m} \times 0.25 \mathrm{~mm} \times 0.25$ $\mu \mathrm{m})$, injection port at $250{ }^{\circ} \mathrm{C}, 1 \mu \mathrm{L}$ splitless injection, and a temperature program starting at $100{ }^{\circ} \mathrm{C}$ (hold $2 \mathrm{~min}$ ), ramp of $3{ }^{\circ} \mathrm{C} / \mathrm{min}$ to $180^{\circ} \mathrm{C}$, hold for $5 \mathrm{~min}$, ramp of $3{ }^{\circ} \mathrm{C} / \mathrm{min}$ to 200 ${ }^{\circ} \mathrm{C}$, hold for $5 \mathrm{~min}$, and a final ramp of $15^{\circ} \mathrm{C} / \mathrm{min}$ to $250^{\circ} \mathrm{C}$, and hold for $3 \mathrm{~min}$. The mass spectrometer ion source was at $250{ }^{\circ} \mathrm{C}$, and the interface temperature was at $260{ }^{\circ} \mathrm{C}$. The resulting peaks were analyzed using the NIST library. The major components were identified by comparison with standard compounds. 

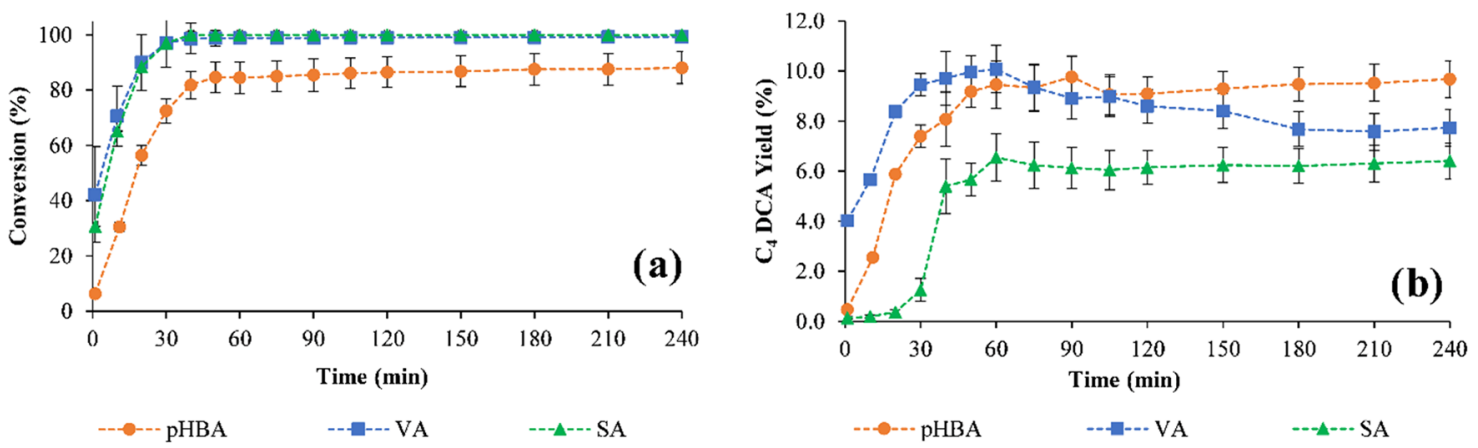

Figure 4. (a) Model compound conversion and (b) $\mathrm{C}_{4}$-DCA yield, at $T=140{ }^{\circ} \mathrm{C}$.

Table 3. Reaction Rate Constants $(k)$ for Model Compound Conversion, at 140 and $120{ }^{\circ} \mathrm{C}$, Based on a Pseudo-First-Order Kinetic Equation

\begin{tabular}{cccc} 
& $p$-hydroxybenzoic acid & vanillic acid & syringic acid \\
$k_{140}{ }^{\circ} \mathrm{C}\left(\mathrm{s}^{-1}\right)$ & $(7.2 \pm 0.3) \times 10^{-4}$ & $(1.7 \pm 0.2) \times 10^{-3}$ & $(1.8 \pm 0.2) \times 10^{-3}$ \\
$k_{120}{ }^{\circ} \mathrm{C}\left(\mathrm{s}^{-1}\right)$ & $(3.2 \pm 0.4) \times 10^{-4}$ & $(3.4 \pm 0.2) \times 10^{-4}$ & $(5.1 \pm 0.2) \times 10^{-4}$ \\
\hline
\end{tabular}

\section{RESULTS AND DISCUSSION}

Oxidation of Model Compounds: $p$-Hydroxybenzoic Acid ( $p H B A$ ), Vanillic Acid (VA), and Syringic Acid (SA).

The model compounds presented different behaviors when oxidized using $\mathrm{H}_{2} \mathrm{O}_{2}$ at $140{ }^{\circ} \mathrm{C}$. Figure 4 shows that both VA and SA reached a nearly full conversion at $40 \mathrm{~min}$ ( 99 and 100 wt $\%$, respectively). However, $p \mathrm{HBA}$ reached a lower conversion, namely, $88 \mathrm{wt} \%$, never being fully converted, even after $4 \mathrm{~h}$ of reaction (even with enough $\mathrm{H}_{2} \mathrm{O}_{2}$ to reach complete mineralization, showing that the remaining oxidant was used to oxidize the produced compounds instead of $p \mathrm{HBA})$. Table 3 summarizes the conversion rates for each tested model compound at $140{ }^{\circ} \mathrm{C}$, where SA and VA showed higher conversion rates, while for $p \mathrm{HBA}$, the lowest one was observed ( $88 \mathrm{wt} \%)$. It has been reported that SA is more reactive than VA when oxidized using $\mathrm{O}_{2}$ at an alkaline $\mathrm{pH}^{30,31}$ However, when $\mathrm{H}_{2} \mathrm{O}_{2}$ at neutral $\mathrm{pH}$ is used, which has higher oxidizing power, no significant differences between $\mathrm{SA}$ and VA conversions were detected.

Lower reaction rates were found at $120^{\circ} \mathrm{C}$, as seen in Table 3. There was no significant difference between VA and $p H B A$ oxidation at this temperature, while SA oxidation occurred faster, confirming its higher reactivity. Therefore, it can be concluded that $p \mathrm{HBA}$ maintained the low reactivity even at higher temperatures, while SA showed the highest reactivity.

The phenolic $\mathrm{OH}$ bond's strength explains most of the reactivity observed for the model compounds because it is the initial site where the compound reacts against a radical. ${ }^{32}$ After the phenolic $\mathrm{OH}$ bond is cleaved by accepting a radical, the radical is delocalized in the aromatic ring, which is reorganized as a quinone to be further oxidized and undergo ring-opening reactions. ${ }^{32}$ The bond-dissociation energy (BDE) for the phenolic $\mathrm{OH}$ bond, a parameter that measures the energy needed to cause the rupture of the bond, is affected by the presence of activating and deactivating groups in the aromatic ring, which can or cannot stabilize the radical by resonance and/or inductive effects. A compound with a lower BDE would show a higher reactivity against an oxidant because the $\mathrm{OH}$ bond would be cleaved easily, and the aromatic ring would be further oxidized to a quinone structure. ${ }^{32,33}$ As the aromatic ring becomes activated, the radical is easily dislocated in the aromatic structure, being more reactive against $\mathrm{H}_{2} \mathrm{O}_{2}$ oxidation. ${ }^{34}$ The highest $\mathrm{BDE}$ is presented by $p \mathrm{HBA}$ ( 85.15 $\mathrm{kcal} / \mathrm{mol})$ when compared to VA $(79.41 \mathrm{kcal} / \mathrm{mol})$ and SA $(79.42 \mathrm{kcal} / \mathrm{mol}),{ }^{33}$ because the latter two compounds have methoxy groups in the ortho position to the phenolic $\mathrm{OH}$ (Figure $1 \mathrm{~b}$ ), which act as electron donors, stabilizing the radical in the aromatic ring. Even though SA has two methoxy groups and VA only one, there is no significant difference between the two compounds due to the intramolecular hydrogen bond formed between the phenolic hydrogen and the methoxy oxygen in SA, stabilizing the phenolic $\mathrm{OH}$ bond. ${ }^{33}$ It is expected that the real $\mathrm{BDE}$ for each model compound in solution is lower than the reported one because the reactions were carried out, at all moments, at a $\mathrm{pH}$ higher than the respective $\left.\mathrm{p} K_{\mathrm{a} 1}(p \mathrm{HBA}=4.57, \mathrm{VA}=4.42, \mathrm{SA}=4.34)\right)^{35,36}$ Over $\mathrm{p} K_{\mathrm{a}}$, the carboxylic acid group was unprotonated, acting as a weak electron donor group by the inductive effect, thus stabilizing the radical in the aromatic ring. ${ }^{37}$ In the opposite case, i.e., if the carboxylic group is protonated, it acts as a deactivating group, slightly destabilizing the radical in the aromatic ring.

After $40 \mathrm{~min}$ of reaction, and for the three compounds, the first-order kinetic model did not fit the experimental data. At this point, a change in the $\mathrm{pH}$ was observed; namely, it decreased from $\mathrm{pH} 7$ to $4.0-5.5$ and then increased to $\mathrm{pH}$ 6.3-7.4 (Figure S1). These facts evidenced a change in the reactions taking place after this time. The degraded model compounds were oxidized to other compounds, namely, dicarboxylic acids, while the remaining model compounds continued to be oxidized but at a lower rate. However, after 40 min, conversion of model compounds reached more than $96 \%$ of the total conversion, i.e., the conversion registered for 240 min reaction time, confirming that the expressed kinetic constant rate explained the main behavior of the model compound conversion.

As the reaction proceeded, VA, and $p \mathrm{HBA}$ solutions turned darker due to the production of chromophoric compounds, such as quinones and condensed aromatic rings. The condensation reactions occurred in these model compounds due to the ortho available position, having two available positions in $p \mathrm{HBA}$ and just one in VA since these positions were activated for addition and condensation reactions. When SA was oxidized, an initial darker color was produced while 
heating the mixture to the reaction temperature, caused by the presence of quinones produced by auto-oxidation. However, as soon as $\mathrm{H}_{2} \mathrm{O}_{2}$ was added, they were quickly degraded, and the color disappeared after a short time. As SA has no available ortho positions to the phenolic $\mathrm{OH}$, no condensation reactions occurred, and no darker solutions were formed. ${ }^{32}$

The methoxylated model compounds were oxidative demethoxylated during the first steps of oxidation, resulting in hydroxyl groups in the aromatic structure. Demethoxylation is achieved when a hydroxyl radical attacks the position where the methoxyl group is linked, retaining this radical as a hydroxyl group while the methoxyl group is released as methanol. ${ }^{38,39}$ This step was observed in VA and SA, where 3,4-dihydroxybenzoic acid (protocatechuic acid) was detected during the first minutes of the reaction by GC-MS analysis. This compound is more reactive than VA and SA, having a lower BDE $(74.44 \mathrm{kcal} / \mathrm{mol}),{ }^{33}$ so it was oxidized faster to $o$ quinones. This compound was also found in $p H B A$ oxidation, suggesting that the hydroxyl radical attacked the carbon adjacent to the $\mathrm{OH}$ group. It is interesting to note that 3,4,5trihydroxybenzoic acid was not found in any oxidation, suggesting that as soon as the 3,4-dihydroxybenzoic acid was obtained it was oxidized to $o$-quinone instead of oxidizing the remaining ortho position to the trihydroxy acid.

Ring-Opening Reaction Main Products: $C_{4}$ Dicarboxylic Acids. Amongst the different compounds produced during the oxidation process, $\mathrm{C}_{4}$-DCA were the main components in the mixture. They resulted from the aromatic ring-opening reaction, which required a strong oxidant. Figure 4.b shows how the concentration of the total $\mathrm{C}_{4}$-DCA (which is the sum of succinic, maleic, malic, tartaric, and fumaric acids) changed through time, reaching a higher yield at $60 \mathrm{~min}$ for SA, at 50-60 min for VA, while for $p H B A$ the highest yield was achieved at $90 \mathrm{~min}$.

However, $\mathrm{C}_{4}$-DCA were not the only acids produced. Other carboxylic acids, like formic, acetic, malonic, and oxalic acids, were identified and quantified, and their total concentration is presented conjunctly as "Other CA" in Figure 5. Most of these acids corresponded to degradation products of $\mathrm{C}_{4}$-DCA, indicating an overoxidation. These acids increased their concentration through time, especially when $p \mathrm{HBA}$ was used as the starting compound, with the highest yield, $24.2 \mathrm{wt} \%$, achieved at $75 \mathrm{~min}$. VA gave rise to $17.3 \mathrm{wt} \%$ at $20 \mathrm{~min}$, while SA to 12.9 wt $\%$ at $150 \mathrm{~min}$. The remaining carbon, not

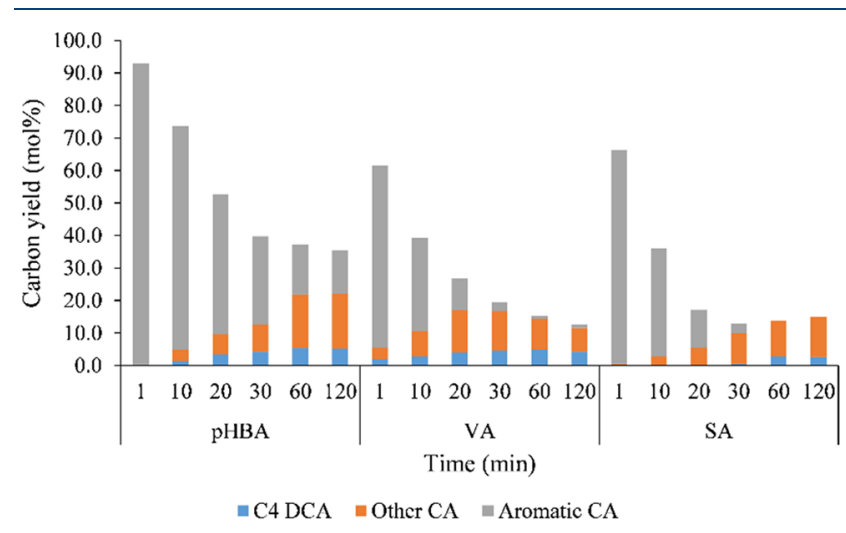

Figure 5. Carbon yield by families, based on the carbon proportion. (C-DCA: succinic, malic, maleic, tartaric and fumaric acids; Other CA: malonic, oxalic, acetic, and formic acids; Aromatic CA: VA, SA, $p \mathrm{HBA})$. quantified in this graphic representation, corresponds to gas losses (mainly $\mathrm{CO}_{2}$ ) and nonquantified products in the solution.

All of the performed reactions started at neutral $\mathrm{pH}$ because it has been reported that many dicarboxylic acids are degraded in acidic conditions, even at lower temperatures. ${ }^{25,40}$ In contrast, at alkaline $\mathrm{pH}$, many hydroxylated acids are obtained, which can be further oxidized to low-molecular-weight acids. ${ }^{41}$ Also, in alkaline conditions, more condensation products have been observed. The major observed $\mathrm{C}_{4}$-DCA was succinic acid in all cases, with a lower amount of maleic acid in $p \mathrm{HBA}$ and tartaric acid in VA oxidations, as seen in Figure 6. Malic, fumaric, and tartaric acids were detected in small quantities in all cases.

In $p$ HBA oxidation, the main acid obtained was succinic acid (5.4 wt \%), while for maleic and fumaric acids production of up to 3.0 and 0.8 wt \%, respectively, was observed. During the first $90 \mathrm{~min}$, traces of malic acid were detected, the signal being very close to the limit of quantification, explaining its appearance and disappearance in several samples. After 90 min, the signal disappeared completely. Maleic acid concentration increased during the first $30 \mathrm{~min}$ and then decreased, being converted to other compounds, such as fumaric, malic, and succinic acids.

In VA oxidation, succinic acid was also the highest produced acid, achieving a maximum of $5.3 \mathrm{wt} \%$ at $60 \mathrm{~min}$, then stabilizing up to $240 \mathrm{~min}$. Malic acid was observed at the very first minutes, with a highest amount of $2.1 \mathrm{wt} \%$, thus decreasing slowly until its disappearance after $180 \mathrm{~min}$. Fumaric acid reached the highest yield ( 0.4 wt \%) at 20 min, maintaining this percentage for the remaining time. Tartaric acid was also found at low concentrations for several minutes. The presence of tartaric and malic acids was associated with the hydroxylation of the double bond present in the maleic acid, which was the first obtained acid after the ring cleavage when $p$-quinone structures were oxidized. ${ }^{41}$ Maleic acid behavior was similar to the one observed in the $p$ HBA reaction, increasing its concentration in the first $20 \mathrm{~min}$, then decreasing due to conversion to other compounds.

In $\mathrm{SA}$ oxidation, succinic acid was practically the only $\mathrm{C}_{4}$ DCA present in the mixture, with the highest amount of $3.8 \mathrm{wt}$ $\%$. For several minutes, small quantities of maleic ( $0.4 \mathrm{wt} \%)$ and fumaric $(0.1 \mathrm{wt} \%)$ acids were observed, but these compounds disappeared after $60 \mathrm{~min}$ of reaction. No hydroxylated acids were quantified during the analyzed reaction time.

GC-MS analysis allowed identifying more compounds (presented in Table S1 and their chemical structures in Figure S2). Among them, different carboxylic acids were found, most of them precursors (e.g., isocitric, cis-aconitic, and 2,5furandicarboxylic acids) or derivatives from the already quantified DCA (e.g., itaconic, tartronic, glycolic, and glyceric acids). The presence of these compounds was directly related to the oxidized model compounds, and therefore correlated to the original structure. With this data, it was possible to establish the oxidation pathway for each model compound and, consequently, to study the effect of the methoxy substituents in the aromatic structure toward the production of $\mathrm{C}_{4}$-DCA.

Figure 7 shows the oxidation pathway for $p \mathrm{HBA}$, which was identified after a detailed analysis of the data included in Table S1. Since the hydroxyl group in $p \mathrm{HBA}$ activated the aromatic ring, the first step in the oxidation was the hydroxylation in the ortho position, forming 3,4-dihydroxybenzoic acid, as con- 

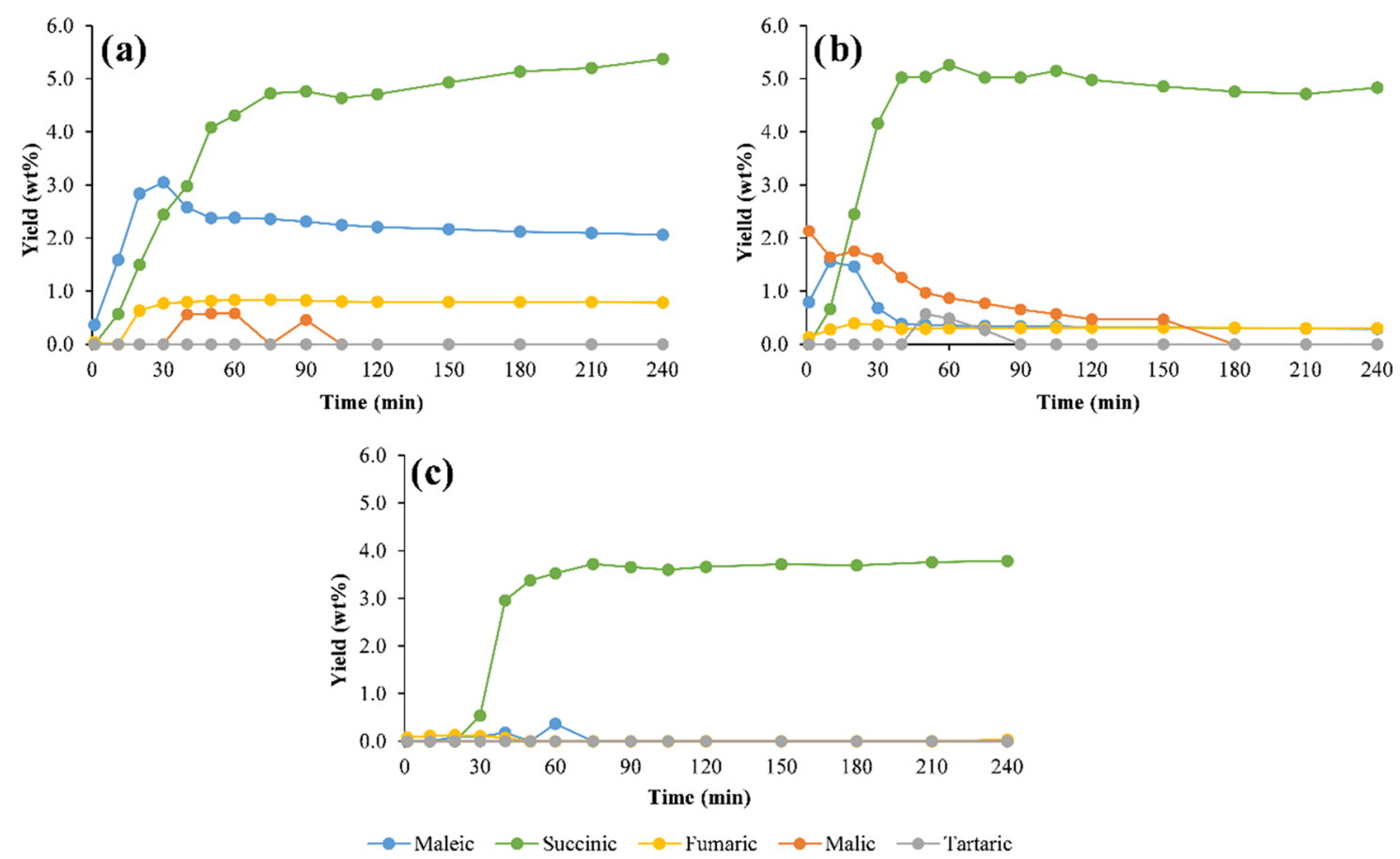

Figure 6. $\mathrm{C}_{4}$-DCA yield for model compound oxidation: (a) $p \mathrm{HBA}$, (b) VA, and (c) SA, at $140{ }^{\circ} \mathrm{C}$.

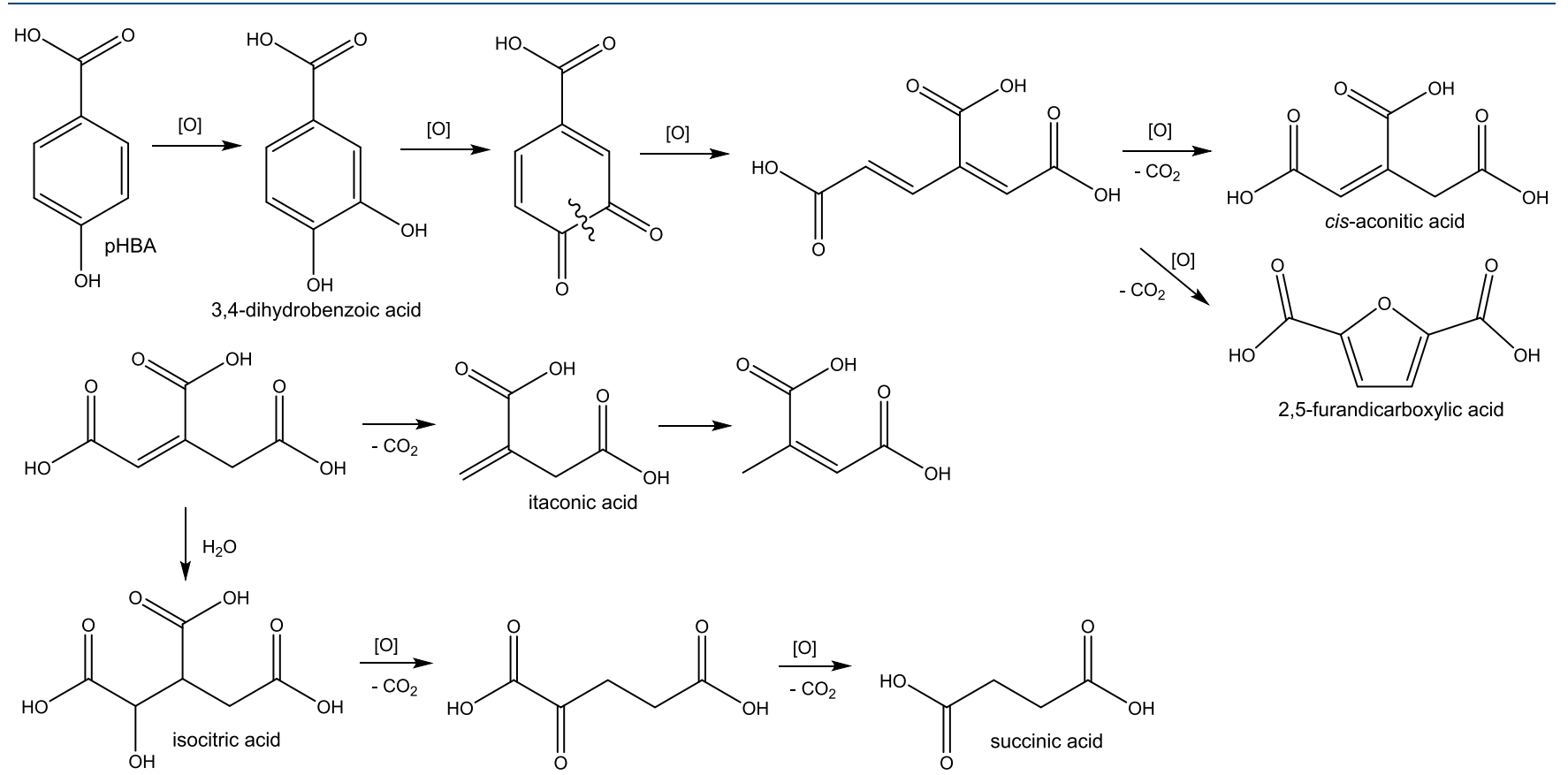

Figure 7. Proposed pathway for $p$-hydroxybenzoic acid oxidation to achieve succinic and itaconic acids.

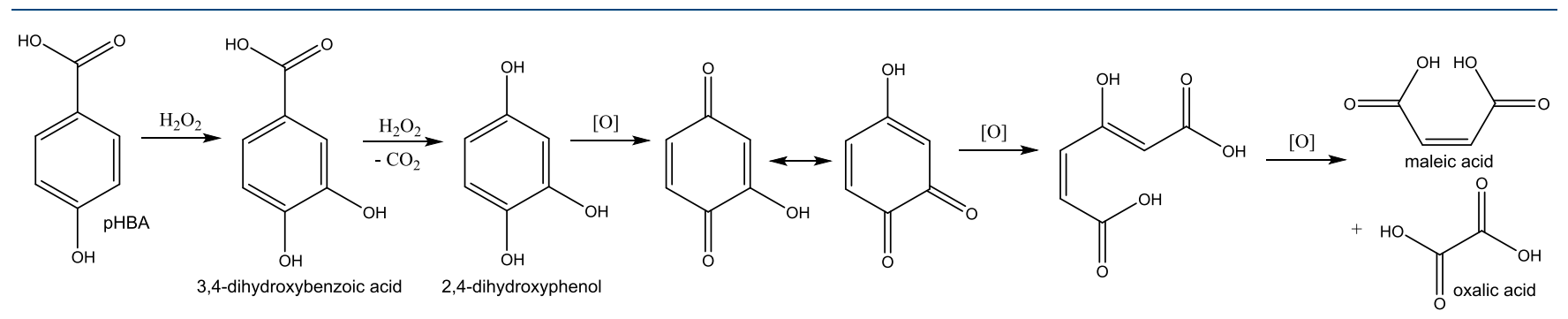

Figure 8. Proposed pathway for $p$-hydroxybenzoic acid oxidation to achieve maleic and oxalic acids. 


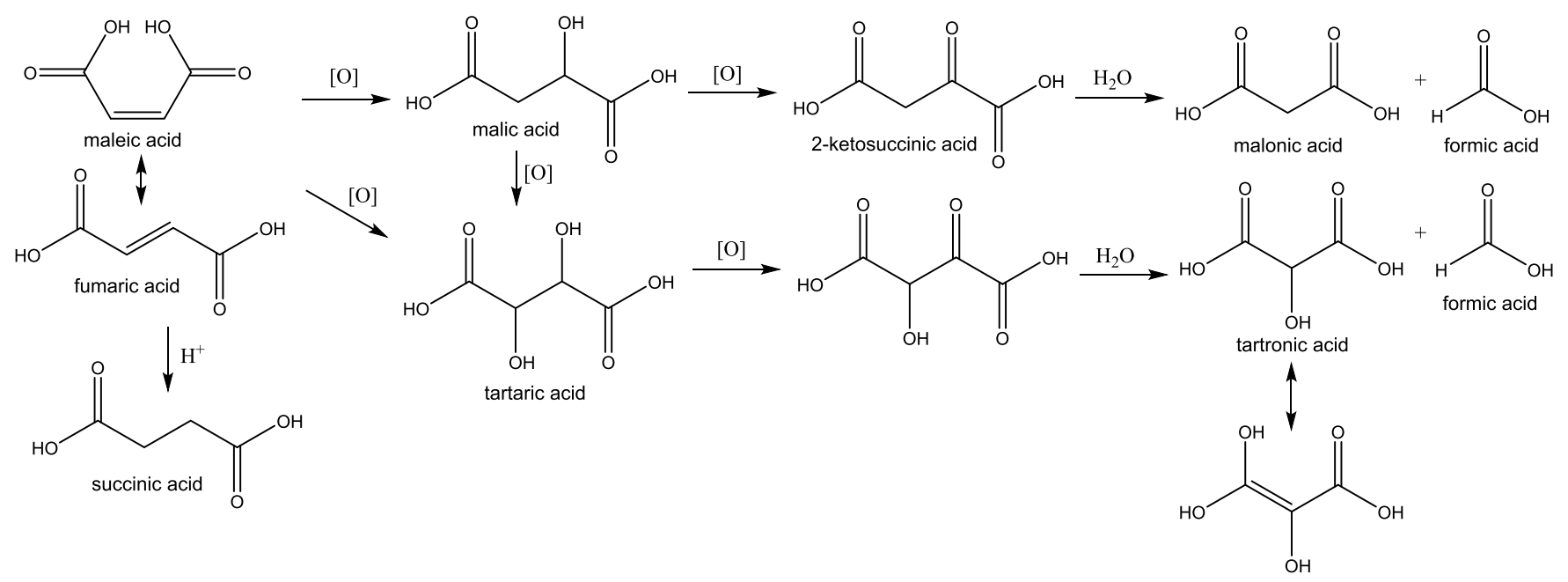

Figure 9. Proposed pathway for maleic acid conversion.

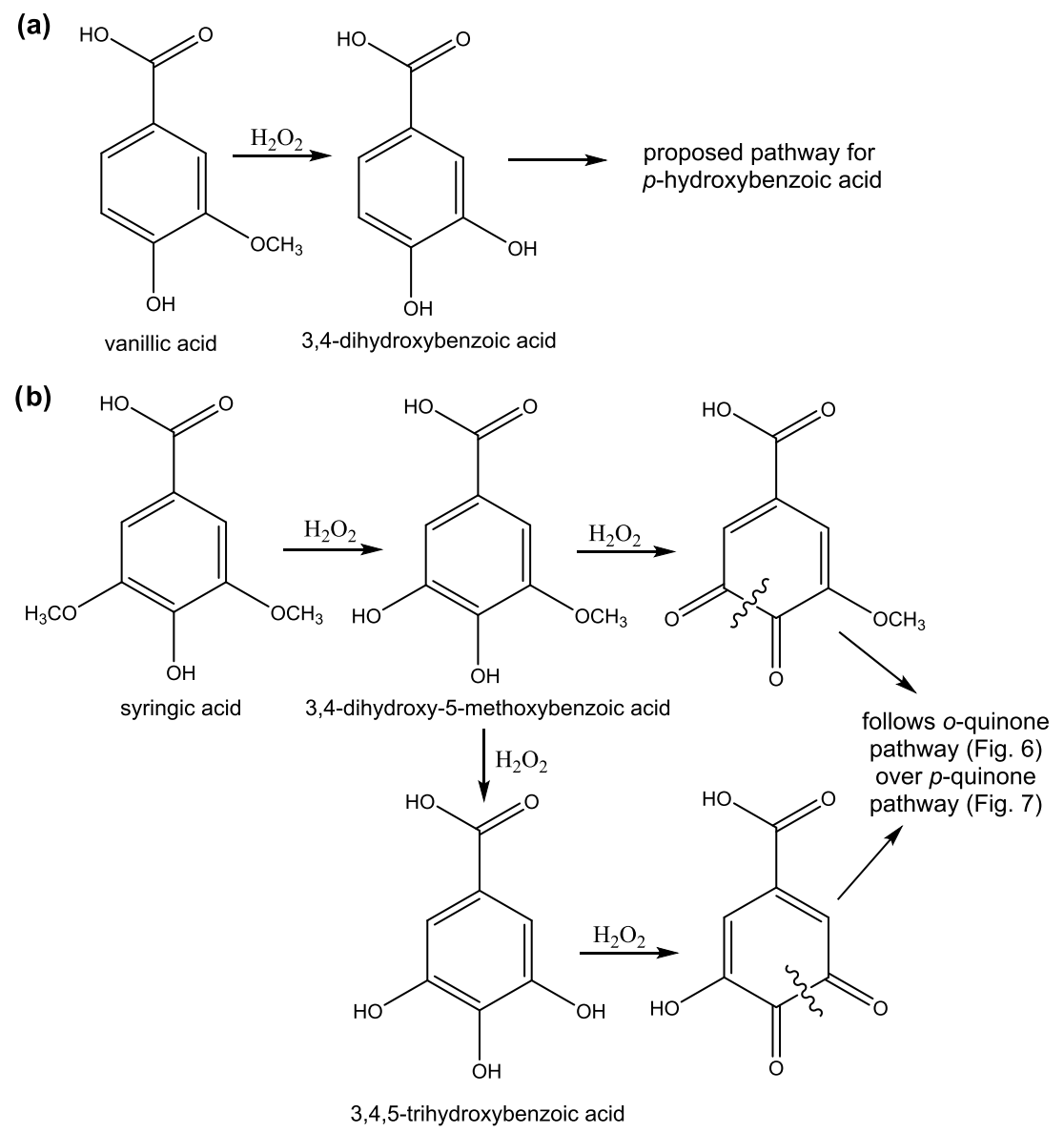

Figure 10. Proposed pathways for (a) vanillic acid and (b) syringic acid.

firmed by Kang et al. ${ }^{42}$ Later, the hydroxyl groups were oxidized to a $o$-benzoquinone structure, which underwent a ring-opening reaction, to obtain a muconic acid derivative. ${ }^{13,22}$ After decarboxylation, several 6-carbon dicarboxylic acids were obtained, like cis-aconitic acid or 2,5-furandicarboxylic acid. These compounds were very reactive, and the cis-aconitic acid was decarboxylated to itaconic acid or converted to isocitric acid, being oxidized and decarboxylated to succinic acid. Most of these compounds showed a high response in GC-MS, confirming their presence along the reaction course. $p$ HBA can also react through a $p$-benzoquinone structure, as detailed in Figure 8. To form the $p$-benzoquinone structure, it must be first oxidized to 3,4-dihydroxybenzoic acid and then decarboxylated to 2,4-dihydroxyphenol, which could then be oxidized to a $p$-benzoquinone derivative. Later, this structure underwent a ring-opening reaction and a rearrangement to obtain maleic and oxalic acids as the main products.

Due to the double bond in maleic acid, this compound could be later oxidized to other compounds, such as malic acid and tartaric acid, as shown in Figure 9. These acids could be further 

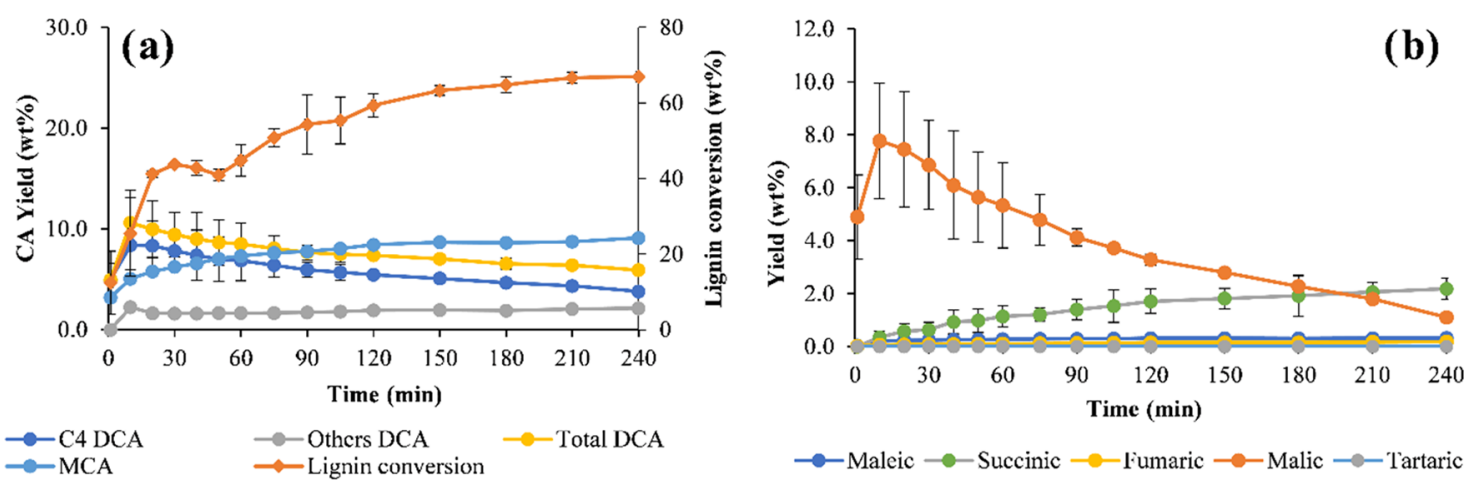

(b)

Figure 11. Indulin AT lignin oxidation with $\mathrm{H}_{2} \mathrm{O}_{2}$, at $140{ }^{\circ} \mathrm{C}$; (a) CA yield $\left(\mathrm{C}_{4}\right.$-dicarboxylic acids [DCA], other DCA, and monocarboxylic acids [MCA]) and lignin conversion; (b) $\mathrm{C}_{4}$-DCA yield.

degraded to low-molecular-weight compounds, such as malonic acid, tartronic acid, 2,3,3-trihydroxy-2-propenoic acid, and formic acid.

The proposed pathway has been established for $p$ hydroxybenzoic acid oxidation, but it can also explain vanillic and syringic acid oxidation. However, some changes should be mentioned to elucidate the observed differences in the produced compounds and their respective yields due to the presence of methoxy substituents.

Vanillic acid has a methoxy group in the ortho position to the $\mathrm{OH}$ group. However, one of the first steps in the oxidation was the demethoxylation, as suggested by several authors, ${ }^{38,39,43}$ forming 3,4-dihydroxybenzoic acid, as shown in Figure 10a. This compound was the starting point of the oxidation in the pathway shown in Figure 7 for $p$ HBA, therefore avoiding the aromatic ring's hydroxylation step. Both VA and $p H B A$ followed the same reaction pathway, expecting to obtain the same products, especially for $\mathrm{C}_{4}$-DCA, as confirmed by the results presented in Figure 6 and Table S1. The main difference lay in the obtained yield for $\mathrm{C}_{4}$-DCA, which was higher for VA oxidation, and derived from the higher reactivity of the aromatic ring due to the presence of the methoxy group as an activating group, as explained before.

SA oxidation behaved slightly differently, having as the main product succinic acid accompanied by lower amounts of other $\mathrm{C}_{4}$-DCA. The small traces of maleic and fumaric acids were explained because when the molecule was demethoxylated, it formed 3,4,5-trihydroxybenzoic acid or 3,4-dihydroxy-5methoxybenzoic acid, compounds that were easily oxidized to o-quinone derivatives (Figure 10b). Decarboxylation had been reported in the first steps for SA oxidation ${ }^{39}$ but their products were not observed in the present study. The possibility of the reaction through the $o$-quinone pathway (Figure 7) is higher than through the $p$-quinone pathway (Figure 8) because various $o$-quinone derived structures were produced, leading to a higher yield of succinic acid and a lower amount of maleic and fumaric acids. The absence of maleic and fumaric acids explained the nonappearance of malic and malonic acids, which were obtained from hydroxylation and further decarboxylation of fumaric/maleic acids, as shown in Figure 9. A similar behavior concerning the low yield of maleic and fumaric acids was observed by Sun et al. ${ }^{43}$ when lignin model compounds were oxidized with $\mathrm{H}_{2} \mathrm{O}_{2}$ using UV radiation. Also, SA oxidation generated propane-1,2,3tricarboxylic acid (Table S1), which was more stable than cis-aconitic acid due to the lack of an unsaturated bond, avoiding the production of succinic acid at yields as high as the ones observed for VA and $p \mathrm{HBA}$ oxidation.

Summarizing, it can be concluded that syringic acid oxidation mainly produced succinic acid at a higher selectivity. However, vanillic acid produced succinic acid at a yield higher (5.3 wt \%) than syringic acid oxidation (3.8 wt \%). The oxidation of $p \mathrm{HBA}$ gave rise to the highest succinic acid yield (up to $5.7 \mathrm{wt} \%$ after $4 \mathrm{~h}$ ), but mixed with other acids at higher concentrations, with the disadvantage of needing several hours to achieve a competitive yield, when compared to the faster reaction undergone by VA and SA. Regarding other $\mathrm{C}_{4}$-DCA, only VA produced malic acid at significant yields, while $p \mathrm{HBA}$ produced unsaturated $\mathrm{C}_{4}$-DCA.

Oxidation of Hardwood and Softwood Lignin. Lignin was oxidized to evaluate the behavior observed with model compounds using real samples. For that reason, two lignins with different proportions of structural units, one from softwood and another from hardwood were chosen. Both lignins are derived from the kraft pulping process, hence avoiding any difference associated with the pulping process. Indulin AT, chosen as the softwood lignin, is commercialized by MeadWestvaco Corporation, having a $\mathrm{S} / \mathrm{G} / \mathrm{H}$ ratio of $0: 97: 3 .^{27}$ The hardwood lignin was isolated from a black liquor obtained from a E. globulus kraft pulping mill (The Navigator Company, Portugal), presenting a $\mathrm{S} / \mathrm{G} / \mathrm{H}$ ratio of $65: 29: 6^{28}$ The two lignins were chosen to represent kraft hardwood and softwood lignins. Since it was not possible to find hardwood and softwood lignins from the same provider, thus guaranteeing the application of the same process, this option was considered adequate to conduct the present study. Both lignins were solubilized in a $0.1 \mathrm{~mol} / \mathrm{L}$ phosphate buffer to ensure that the lignin was at a $\mathrm{pH}$ around 7 during the oxidation process, avoiding precipitation in an acidic environment. However, this buffer caused a partial degradation of peroxide inside the reactor, therefore lowering its oxidation potential.

Figure 11 summarizes the results obtained for Indulin AT (softwood lignin) conversion after $4 \mathrm{~h}$, which was $68 \%$. The amount of monocarboxylic acids (obtained from lignin degradation into $\mathrm{C}_{4}$-DCA) increased up to $14 \mathrm{wt} \%$ after 4 h. Malic and succinic acids were the main DCA obtained; the malic acid yield was high at the starting of the reaction $(8.0 \mathrm{wt}$ $\%$ at $10 \mathrm{~min}$ ), but then decreased to $1.0 \mathrm{wt} \%$ after $4 \mathrm{~h}$, while the succinic acid yield increased slowly, reaching a maximum of $2.5 \mathrm{wt} \%$ at the end of the reaction $(240 \mathrm{~min})$. Small quantities of maleic and fumaric acids were also observed but at yields lower than 0.30 wt \%. 

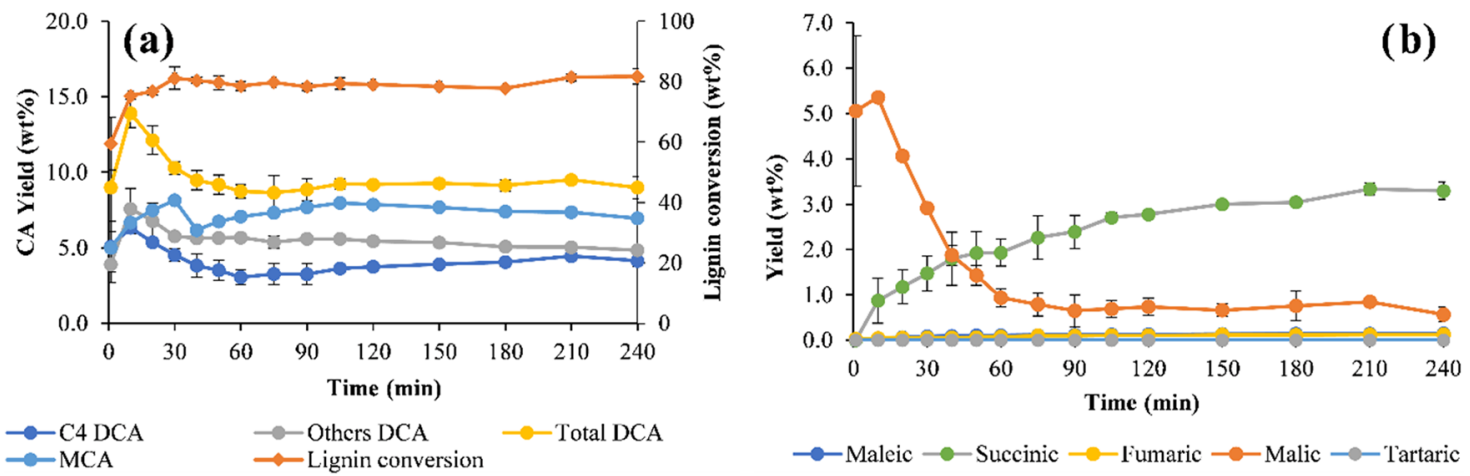

Figure 12. Hardwood lignin oxidation with $\mathrm{H}_{2} \mathrm{O}_{2}$, at $140{ }^{\circ} \mathrm{C}$; (a) CA yield $\left(\mathrm{C}_{4}\right.$-dicarboxylic acids [DCA], other DCA, and monocarboxylic acids [MCA]) and lignin conversion; (b) $\mathrm{C}_{4}$-DCA yield.

Figure 12 illustrates that E. globulus kraft lignin (hardwood lignin) oxidation reached a total conversion of $83 \%$ after 30 min, then remained practically constant. $\mathrm{C}_{4}$-DCA were also produced in the first minutes, while the monocarboxylic acids' yield increased, but only slightly when compared to softwood lignin. The main DCA obtained were also malic and succinic acids. Malic acid showed the same behavior as the one observed for Indulin AT lignin, i.e., achieving a high yield at the starting of the reaction $(5.3 \mathrm{wt} \%$ at $10 \mathrm{~min}$ ) but then decreasing quickly to $0.5 \mathrm{wt} \%$ after $4 \mathrm{~h}$. Succinic acid yield increased, reaching a maximum of $3.2 \mathrm{wt} \%$. Small quantities of maleic and fumaric acids were detected but at yields lower than 0.13 wt $\%$.

The presence of malic acid during the first minutes of the reaction was associated with the high content of guaiacyl units in both lignins, which result was similar to the one observed for VA oxidation. In this case, softwood lignin was composed mainly of guaiacyl units and therefore produced more malic acid than hardwood lignin, which has a $S / G$ ratio of $65: 29$. However, the higher yield of malic acid observed during the reaction starting phase in both lignins, comparatively with VA oxidation, could be caused by the solution's slightly different $\mathrm{pH}$ conditions. When lignins were oxidized, the buffer kept the $\mathrm{pH}$ around 6.5-7.0 during the overall reaction avoiding lignin precipitation. In contrast, in the model compound oxidation, which was done without a buffer, the medium was quickly acidified and then back to neutral $\mathrm{pH}$ (Figure S1). When the reaction took place at a higher $\mathrm{pH}$, there was a higher chance to obtain hydroxylated compounds in the peroxide oxidation, as previously reported. ${ }^{41}$ During the first minutes of model compound oxidation, the acidic $\mathrm{pH}$ could prevent malic acid formation at high yields, converting any produced malic acid to succinic acid. Even though malic acid was obtained at high yields during the first minutes of lignin oxidation, it was quickly converted to succinic acid or degraded to low-molecularweight compounds due to the slightly acidic environment.

E. globulus kraft lignin gave rise to the highest conversion in the first $30 \mathrm{~min}$, while Indulin AT needed more than $210 \mathrm{~min}$ to reach the highest conversion, but without attaining the level achieved for hardwood lignin. It has been reported that hardwood lignins are more reactive toward peroxide oxidation when compared to softwood lignins due to structural differences. ${ }^{14,26}$ Since the hardwood lignin had a higher S/G ratio, it became more reactive against peroxide oxidation due to the high content of S units, which was also observed in SA comparatively to VA.
VA showed a higher succinic acid yield than SA oxidation, so softwood lignin was expected to result in a higher succinic acid yield, based only on the lower $S / G$ ratio (due to higher content on guaiacyl units). However, due to $S$ groups' higher reactivity, hardwood lignin (with a higher $S / G$ ratio) had a higher reactivity and was degraded easily. This fact helped open the lignin structure, making more lignin fractions available for further oxidation toward DCA and presenting a slightly better succinic acid yield, as observed in Figure 12. It was also noticed that E. globulus kraft lignin oxidation produced succinic acid faster than Indulin AT lignin, while malic acid was also degraded faster. In several studies, lignin peroxide oxidation using lignins with a high $S / G$ ratio showed a higher yield for dicarboxylic acids than lignins based on guaiacyl moieties (softwood lignins), especially under an acidic $\mathrm{pH}^{16,23,26,44} \mathrm{Ma}$ et $\mathrm{al}^{26}$ reported that a higher amount of methoxy groups in lignin had a positive effect on the total dicarboxylic acid yield (quantified in their work as $\mathrm{C}_{2}-\mathrm{C}_{6}$ DCA, and not only $\mathrm{C}_{4}$-DCA), while the presence of these groups had a negative influence on lignin depolymerization to monomeric phenolic compounds. Although methoxy groups apparently hindered lignin depolymerization to phenolic compounds, they activated the aromatic ring creating electron-rich areas that competed with the alkyl side chains between aromatic lignin monomeric units, enhancing ringopening reactions. Hardwood lignin showed a higher yield of the total DCA, as seen in Figures 11a and 12a. Therefore, this work's findings corroborated the model proposed by Ma et al. for DCA production, even though this model was not entirely focused on $\mathrm{C}_{4}$-DCA. Still, DCA yields changed through time, especially with softwood lignin (due to malic acid degradation), which was not considered in their model. They evaluated a specific point of the reaction time and not the variations along time giving rise to DCA production and degradation.

In conclusion, the E. globulus kraft lignin seems to be a better lignin than Indulin AT to obtain succinic acid by peroxide oxidation. It was degraded faster than Indulin AT lignin, produced malic acid, and other acids at lower yields, and gave rise to succinic acid at higher yields through a faster reaction. This finding confirmed that lignins with a higher $S / G$ ratio could be better for peroxide oxidation and ring-opening reactions toward $\mathrm{C}_{4}$-DCA, especially succinic acid. However, it should be noted that a more detailed analysis should include the different bonding structures of lignin, which vary from biomass to biomass and the used pulping techniques. Namely, lignins with high condensation degrees have been reported as very stable toward oxidation. Future studies must be 
conducted to increase and optimize $\mathrm{C}_{4}$-DCA yields, taking into account the type and origin of lignin, the reactor design, and presence of catalysts. Moreover, the profit exploitation of lignin must consider a cascade of products in its value chain, for which $\mathrm{C}_{4}$-DCAs can contribute.

\section{CONCLUSIONS}

This study demonstrated that $p$-hydroxybenzoic acid, vanillic acid, and syringic acid peroxide oxidation produced $\mathrm{C}_{4}$ dicarboxylic acids (succinic, malic, fumaric, maleic, and tartaric acids) at different contents, yields, and kinetics, which was justified by the different amounts of methoxy groups present in the aromatic structure. SA had the higher reactivity toward oxidation, while $p H B A$ had the lower one due to the activation effect of the methoxy groups in the aromatic ring. The observed succinic acid yield followed the relation $p \mathrm{HBA}>\mathrm{VA}$ $>\mathrm{SA}$ but needed longer times for $p \mathrm{HBA}$ to reach a competitive yield. VA and $p$ HBA produced other $\mathrm{C}_{4}$-DCA besides succinic acid, SA oxidation being much more selective toward succinic acid.

When two lignins with different $\mathrm{S} / \mathrm{G} / \mathrm{H}$ ratios were oxidized, the softwood lignin (Indulin AT) produced a lower amount of succinic acid than a hardwood lignin (lignin obtained from $E$. globulus black liquor). Moreover, the hardwood lignin reacted faster than the softwood lignin due to the higher reactivity observed in syringyl units. Both lignins produced malic acid at an initially high yield, then converted to other compounds during the reaction time. Summarizing, it can be concluded that lignins richer in syringyl groups have a higher reactivity toward peroxide oxidation reactions. They are converted faster, producing succinic acid at higher yields, justified by the activation effect of methoxy groups in aromatic rings.

\section{ASSOCIATED CONTENT}

\section{SI Supporting Information}

The Supporting Information is available free of charge at https://pubs.acs.org/doi/10.1021/acs.iecr.0c05085.

Additional graphics of the $\mathrm{pH}$ behavior during model compound oxidation (Figure S1); chemical structures of the compounds detected by GC-MS analysis for $p \mathrm{HBA}$, VA, and SA oxidation with $\mathrm{H}_{2} \mathrm{O}_{2}$ at $140{ }^{\circ} \mathrm{C}$ (Figure S2); a table with the compounds identified by GC-MS for $p$ HBA, VA, and SA oxidation at $140{ }^{\circ} \mathrm{C}$ (Table S1) (PDF)

\section{AUTHOR INFORMATION}

\section{Corresponding Author}

Alírio E. Rodrigues - Laboratory of Separation and Reaction Engineering-Laboratory of Catalysis and Materials (LSRELCM), Faculdade de Engenharia, Universidade do Porto, 4200-465 Porto, Portugal; ○ orcid.org/0000-0002-07154761; Email: arodrig@fe.up.pt

\section{Authors}

Carlos A. Vega-Aguilar - Laboratory of Separation and Reaction Engineering-Laboratory of Catalysis and Materials (LSRE-LCM), Faculdade de Engenharia, Universidade do Porto, 4200-465 Porto, Portugal; Centro de Investigação de Montanha-CIMO, Instituto Politécnico de Bragança, Campus de Santa Apolónia, 5300-253 Bragança, Portugal; (1) orcid.org/0000-0001-8542-8732
M. Filomena Barreiro - Centro de Investigação de Montanha-CIMO, Instituto Politécnico de Bragança, Campus de Santa Apolónia, 5300-253 Bragança, Portugal

Complete contact information is available at: https://pubs.acs.org/10.1021/acs.iecr.0c05085

\section{Author Contributions}

The manuscript was written through contributions of all authors. All authors have given approval to the final version of the manuscript. All authors contributed equally.

\section{Notes}

The authors declare no competing financial interest.

\section{ACKNOWLEDGMENTS}

This work was financially supported by Base Funding UIDB/50020/2020 of the Associate Laboratory LSRE-LCM funded by national funds through FCT/MCTES (PIDDAC); Base Funding-UIDB/00690/2020 of CIMO, Centro de Investigação de Montanha-funded by national funds through FCT/MCTES (PIDDAC); COST Action LignoCOST (CA17128). C.A.V.-A. thanks the Costa Rican Science, Technology and Telecommunications Ministry for the Ph.D. Scholarship MICITT-PINN-CON-2-1-4-17-1-002.

\section{ABBREVIATIONS}

CA carboxylic acids

DCA dicarboxylic acids

HPLC high-performance liquid chromatography

GC-MS gas chromatography-mass spectroscopy

MCA monocarboxylic acids

pHBA $p$-hydroxybenzoic acid

VA vanillic acid

SA syringic acid

\section{REFERENCES}

(1) Gillet, S.; Aguedo, M.; Petitjean, L.; Morais, A. R. C.; da Costa Lopes, A. M.; Łukasik, R. M.; Anastas, P. T. Lignin Transformations for High Value Applications: Towards Targeted Modifications Using Green Chemistry. Green Chem. 2017, 19, 4200-4233.

(2) Li, C.; Zhao, X.; Wang, A.; Huber, G. W.; Zhang, T. Catalytic Transformation of Lignin for the Production of Chemicals and Fuels. Chem. Rev. 2015, 115, 11559-11624.

(3) Brunow, G. Lignin Chemistry And Its Role In Biomass Conversion. In Biorefineries-Industrial Processes And Products; Kamm, B.; Gruber, P. R.; Kamm, M., Eds.; Wiley-VCH Verlag GmbH: Weinheim, Germany, 2005; pp 151-163.

(4) Upton, B. M.; Kasko, A. M. Strategies for the Conversion of Lignin to High-Value Polymeric Materials: Review and Perspective. Chem. Rev. 2016, 116, 2275-2306.

(5) Ponnusamy, V. K.; Nguyen, D. D.; Dharmaraja, J.; Shobana, S.; Banu, J. R.; Saratale, R. G.; Chang, S. W.; Kumar, G. A Review on Lignin Structure, Pretreatments, Fermentation Reactions and Biorefinery Potential. Bioresour. Technol. 2019, 271, 462-472.

(6) Evstigneyev, E. I.; Shevchenko, S. M. Structure, Chemical Reactivity and Solubility of Lignin: A Fresh Look. Wood Sci. Technol. 2019, 53, 7-47.

(7) Sun, Z.; Fridrich, B.; De Santi, A.; Elangovan, S.; Barta, K. Bright Side of Lignin Depolymerization: Toward New Platform Chemicals. Chem. Rev. 2018, 118, 614-678.

(8) Wendisch, V. F.; Kim, Y.; Lee, J. H. Chemicals from Lignin: Recent Depolymerization Techniques and Upgrading Extended Pathways. Curr. Opin. Green Sustainable Chem. 2018, 14, 33-39.

(9) Li, X.; Zheng, Y. Biotransformation of Lignin: Mechanisms, Applications and Future Work. Biotechnol. Prog. 2020, 36, 1-21. 
(10) Tarabanko, V.; Tarabanko, N. Catalytic Oxidation of Lignins into the Aromatic Aldehydes: General Process Trends and Development Prospects. Int. J. Mol. Sci. 2017, 18, No. 2421.

(11) Wendisch, V. F.; Kim, Y.; Lee, J. H. Chemicals from Lignin: Recent Depolymerization Techniques and Upgrading Extended Pathways. Curr. Opin. Green Sustainable Chem. 2018, 14, 33-39.

(12) Rodrigues, A. E.; Pinto, P. C. R.; Barreiro, M. F.; da Costa, C. A. E.; da Mota, M.I.F.; Fernandes, I.P. An Integrated Approach for Added-Value Products from Lignocellulosic Biorefineries; Springer International Publishing: Cham, 2018.

(13) Zeng, J.; Yoo, C. G.; Wang, F.; Pan, X.; Vermerris, W.; Tong, Z. Biomimetic Fenton-Catalyzed Lignin Depolymerization to HighValue Aromatics and Dicarboxylic Acids. ChemSusChem 2015, 8 , 861-871.

(14) Hasegawa, I.; Inoue, Y.; Muranaka, Y.; Yasukawa, T.; Mae, K. Selective Production of Organic Acids and Depolymerization of Lignin by Hydrothermal Oxidation with Diluted Hydrogen Peroxide. Energy Fuels 2011, 25, 791-796.

(15) Cronin, D. J.; Zhang, X.; Bartley, J.; Doherty, W. O. S. Lignin Depolymerization to Dicarboxylic Acids with Sodium Percarbonate. ACS Sustainable Chem. Eng. 2017, 5, 6253-6260.

(16) Bi, Z.; Li, Z.; Yan, L. Catalytic Oxidation of Lignin to Dicarboxylic Acid over the CuFeS2 Nanoparticle Catalyst. Green Process. Synth. 2018, 7, 306-315.

(17) Bhargava, S. K.; Tardio, J.; Prasad, J.; Föger, K.; Akolekar, D. B.; Grocott, S. C. Wet Oxidation and Catalytic Wet Oxidation. Ind. Eng. Chem. Res. 2006, 45, 1221-1258.

(18) Ma, R.; Xu, Y.; Zhang, X. Catalytic Oxidation of Biorefinery Lignin to Value-Added Chemicals to Support Sustainable Biofuel Production. ChemSusChem 2015, 8, 24-51.

(19) Werpy, T.; Petersen, G. Top Value Added Chemicals From Biomass: Volume I--Results Of Screening For Potential Candidates From Sugars And Synthesis Gas; National Renewable Energy Laboratory: Golden, CO (US), 2004.

(20) Du, G.; Liu, L.; Chen, J. White Biotechnology For Organic Acids. In Industrial Biorefineries \& White Biotechnology; Pandey, A.; Höfer, R.; Taherzadeh, M.; Nampoothiri, K. M.; Larroche, C., Eds.; Elsevier, 2015; pp 409-444.

(21) Gierer, J. Chemistry of Delignification- Part 2: Reactions of Lignins during Bleaching. Wood Sci. Technol. 1986, 20, 1-33.

(22) Suzuki, H.; Cao, J.; Jin, F.; Kishita, A.; Enomoto, H.; Moriya, T. Wet Oxidation of Lignin Model Compounds and Acetic Acid Production. J. Mater. Sci. 2006, 41, 1591-1597.

(23) Xiang, Q.; Lee, Y. Y. Oxidative Cracking of Precipitated Hardwood Lignin by Hydrogen Peroxide. Appl. Biochem. Biotechnol. 2000, 84-86, 153-162.

(24) Sun, Y. P.; Nguyen, K. L.; Wallis, A. F. A. Ring-Opened Products from Reaction of Lignin Model Compounds with UVAssisted Peroxide. Holzforschung 1998, 52, 61-66.

(25) Cronin, D. J.; Dunn, K.; Zhang, X.; Doherty, W. O. S. S. Relating Dicarboxylic Acid Yield to Residual Lignin Structural Features. ACS Sustainable Chem. Eng. 2017, 5, 11695-11705.

(26) Ma, R.; Zhang, X.; Wang, Y.; Zhang, X. New Insights toward Quantitative Relationships between Lignin Reactivity to Monomers and Their Structural Characteristics. ChemSusChem 2018, 11, 21462155.

(27) Constant, S.; Wienk, H. L. J.; Frissen, A. E.; Peinder, P. De.; Boelens, R.; Van Es, D. S.; Grisel, R. J. H.; Weckhuysen, B. M.; Huijgen, W. J. J.; Gosselink, R. J. A.; Bruijnincx, P. C. A. New Insights into the Structure and Composition of Technical Lignins: A Comparative Characterisation Study. Green Chem. 2016, 18, 26512665

(28) Costa, C. A. E.; Pinto, P. C. R.; Rodrigues, A. E. Lignin Fractionation from Eucalyptus globulus Kraft Liquor by Ultrafiltration in a Three Stage Membrane Sequence. Sep. Purif. Technol. 2018, 192, $140-151$.

(29) Rohde, V.; Böringer, S.; Tübke, B.; Adam, C.; Dahmen, N.; Schmiedl, D. Fractionation of Three Different Lignins by Thermal
Separation Techniques-A Comparative Study. GCB Bioenergy 2019, 11, 206-217.

(30) Casimiro, F. M.; Costa, C. A. E.; Botelho, C. M.; Barreiro, M. F.; Rodrigues, A. E. Kinetics of Oxidative Degradation of LigninBased Phenolic Compounds in Batch Reactor. Ind. Eng. Chem. Res. 2019, 58, 16442-16449.

(31) Schutyser, W.; Kruger, J. S.; Robinson, A. M.; Katahira, R.; Brandner, D. G.; Cleveland, N. S.; Mittal, A.; Peterson, D. J.; Meilan, R.; Román-Leshkov, Y.; Beckham, G. T. Revisiting Alkaline Aerobic Lignin Oxidation. Green Chem. 2018, 20, 3828-3844.

(32) Barclay, L. R. C.; Vinqvist, M. R. Phenols as Antioxidants. In The Chemistry of Phenols; Rappoport, Z., Ed.; John Wiley \& Sons, Ltd: Chichester, UK, 2003; pp 839-908.

(33) Mohajeri, A.; Asemani, S. S. Theoretical Investigation on Antioxidant Activity of Vitamins and Phenolic Acids for Designing a Novel Antioxidant. J. Mol. Struct. 2009, 930, 15-20.

(34) Sun, Y.; Fenster, M.; Yu, A.; Berry, R. M.; Argyropoulos, D. S. The Effect of Metal Ions on the Reaction of Hydrogen Peroxide with Kraft Lignin Model Compounds. Can. J. Chem. 1999, 77, 667-675.

(35) Lide, D. R. CRC Handbook of Chemistry and Physics, 90th ed.; Taylor \& Francis, 2009.

(36) Ragnar, M.; Lindgren, C. T.; Nilvebrant, N.-O. PK a -Values of Guaiacyl and Syringyl Phenols Related to Lignin. J. Wood Chem. Technol. 2000, 20, 277-305.

(37) Smith, M. B.; March, J. March's Advanced Organic Chemistry, 6th ed.; John Wiley \& Sons, Inc: Hoboken, NJ, USA, 2006.

(38) Gierer, J.; Yang, E.; Reitberger, T. On the Significance of the Superoxide Radical (O2-/HO2.) in Oxidative Delignification, Studied with 4-t-Butylsyringol and 4-t-Butylguaiacol Part i. the Mechanisrn of Aromatic Ring Opening. Holzforschung 1994, 48, 405-414.

(39) Santos, G. T. A. D.; Santos, P. S. M.; Duarte, A. C. Vanillic and Syringic Acids from Biomass Burning: Behaviour during Fenton-like Oxidation in Atmospheric Aqueous Phase and in the Absence of Light. J. Hazard. Mater. 2016, 313, 201-208.

(40) Di Marino, D.; Jestel, T.; Marks, C.; Viell, J.; Blindert, M.; Kriescher, S. M. A.; Spiess, A. C.; Wessling, M. Carboxylic Acids Production via Electrochemical Depolymerization of Lignin. ChemElectroChem 2019, 6, 1434-1442.

(41) Vega-Aguilar, C. A.; Barreiro, M. F.; Rodrigues, A. E. Catalytic Wet Peroxide Oxidation of Vanillic Acid as a Lignin Model Compound towards the Renewable Production of Dicarboxylic Acids. Chem. Eng. Res. Des. 2020, 159, 115-124.

(42) Kang, J.; Irmak, S.; Wilkins, M. Conversion of Lignin into Renewable Carboxylic Acid Compounds by Advanced Oxidation Processes. Renewable Energy 2019, 135, 951-962.

(43) Sun, Y.-P.; Nguyen, K. L.; Wallis, A. F. A. Ring-Opened Products from Reaction of Lignin Model Compounds with UVAssisted Peroxide. Holzforschung 1998, 52, 61-66.

(44) Ma, R.; Guo, M.; Zhang, X. Selective Conversion of Biorefinery Lignin into Dicarboxylic Acids. ChemSusChem 2014, 7, 412-415. 